\title{
EXTREMA DERECHA Y FASCISMO EN ESPAÑA Y EN EUROPA: ELEMENTOS PARA UN DEBATE
}

\author{
PReSENTACIÓN
}

Las referencias al extremismo de derecha se han hecho más frecuentes en Europa y Norteamérica desde mediados de la década de los ochenta. Quizás esta recuperación del interés por el conservadurismo más intransigente haya tenido que ver con la revitalización del liberalismo como referente político y económico dominante en las sociedades postindustriales, con la proliferación en la escena pública de opciones políticas alternativas (movimientos pacifistas, ecologistas o defensores de los derechos de las minorías) que se reclaman herederas intelectuales del inconformismo de la «Nueva Izquierda», o, sobre todo, con la conciencia de que, en la actualidad, las mayores amenazas para la democracia en los países occidentales proceden de una derecha radical de carácter populista y antigubernamentalista que mezcla el darwinismo económico con una visión profundamente retrógrada de la vida familiar. Sea como fuere, la reacción ultraconservadora enfrentada tanto al statu quo como a sus críticos progresistas aparece ante la luz pública como un conglomerado de individuos, partidos, movimientos y organizaciones tan diversos como los skinheads, booligans, neonazis, supremacistas blancos y racistas, fundamentalistas religiosos, formaciones paramilitares o grupos políticos fanatizados. Lo que no parece ofrecer dudas es que, al igual que la derecha en general, la extrema derecha no presenta una imagen monolítica, sino que impregna múltiples formas políticas, ideologías o comportamientos colectivos. De ahí procede la principal dificultad para su análisis y definición ${ }^{1}$, que resultan especialmente engorrosos cuando

1 Billig, Michael: «The Extreme Right: Continuities in Anti-Semitic Conspiracy Theory in Post-War Europe», en Roger Eatwell y Noël O'sullivan (eds.): The Nature of the Right, Londres, Pinter Publisher, 1989, p. 146. 
abordamos el fenómeno del fascismo en su genealogía y sus vinculaciones teóricas con las corrientes derechistas más o menos adyacentes.

No puede hablarse, en efecto, de una ultraderecha históricamente homogéna, ya que hay tendencias o corrientes derechistas con tradiciones políticas o de pensamiento muy diversas, e incluso enfrentadas entre sí. Para arrojar algo de luz sobre el problema, parece necesario hacer una breve incursión sobre el concepto de derecha, para pasar luego a caracterizar su vertiente más extrema. La antinomia izquierda/derecha es una consecuencia de la modernidad. El pensamiento de derecha nace de la experiencia de la discontinuidad entre el presente y el pasado, que es consecuencia de las relaciones capitalistas de producción y de la secularización provocada por la difusión del racionalismo ilustrado. Para el hombre de derecha, la historia se expresa, "no en forma lineal, sino en la persistencia de estructuras, comunidades, hábitos y prejuicios, generación tras generación ${ }^{2}$. La derecha ha de surgir, pues, en una sociedad donde aparecen signos de dinamismo político, ideológico y económico; de diferenciación específica en clases o grupos sociales enfrentados entre sí. Las mentalidades conservadoras y/o tradicionalistas se convierten en pensamiento conservador o tradicional en una sociedad que empieza a escindirse en grupos sociales, y en cuyo seno comienza a articularse una reacción consciente a formas de pensamiento progresistas.

La idea de extremismo surgió a fines del siglo XIX con el objeto de caracterizar la aparición de actitudes públicas definidas por un intenso activismo político y unos principios ideológicos absolutos e innegociables ${ }^{3}$. Para Lipset y Raab, el término extremismo describe, ante todo, a sectores de derecha o de izquierda que parten de la suposición de estar investidos del monopolio de la verdad política, lo que les lleva a oponerse al pluralismo, a la política del compromiso y al relativismo moral. El extremismo es hostil por naturaleza a la diversidad de intereses y grupos, "hostil a un sistema de muchos centros de poder y zonas de intimidad, que no se someten». Su eje fundamental es «la represión de toda diferencia y disensión, la clausura del mercado de ideas». Para ser más precisos, la esencia vital del extremismo es «la tendencia a tratar como cosa ilegítima toda segmentación o ambivalencia» ${ }^{4}$.

Desde el punto de vista socioeconómico, el extremismo de derecha se ha interpretado como la respuesta desesperada de los perdedores en el proceso de modernización, o como una afección patológica de las sociedades industriales. Así, por ejemplo, Bell lo entendió como una protesta reactiva contra el conjunto de cambios económicos y sociales resultantes del desplazamiento de algunos grupos de población desde antiguas posiciones de poder y status que acompa-

2 NisBét, Robert A.: Conservadurismo, Madrid, Alianza, 1995, pp. 42-43.

3 Ebata, Michi: «Right Wing Extremism: In Search of a Definition», en Aurel Braun y Stephen ScheInberg (eds.): The Extreme Right. Freedom and Security at Risk, Oxford, Westview Pres, 1997 , p. 20.

4 LIPSET, Seymour Martin y RAAB, Earl: La política de la sinrazón. El extremismo de derecha en los Estados Unidos, 1790-1977, México, Fondo de Cultura Económica, 1981, pp. 19 ss.

Hispania, LXI/1, núm. 207 (2001) 9-16 
ñan al progreso ${ }^{5}$. Sin embargo, esta identificación del extremismo de derecha con los relegados en el proceso de modernización no resulta exacta del todo. El análisis que Eduardo González efectúa sobre el peculiar proceso de construcción y deconstrucción a que han sido sometidas las interpretaciones «clásicas» sobre los apoyos sociales del fascismo pone de manifiesto la heterogeneidad del origen social y político de líderes, militantes y votantes. Para calibrar los cambios en la caracterización de clases del fascismo, parece necesario seguir explorando en detalle las variaciones en el apoyo social antes y después de sus ensayos por conquistar el poder en solitario o con apoyos externos, analizar las rupturas y continuidades, describir las tendencias de distribución regional de ese apoyo y desentrañar las funciones sociales de los propios movimientos fascistas.

Si concebimos el extremismo derechista como un «modo de ser» reactivo, ha de ser caracterizado antes que nada por sus expresiones de odio, fanatismo o prejuicio basadas en una «ideología de la desigualdad» $»^{6}$. Es cierto que, en períodos tranquilos, puede identificarse con actitudes como la nostalgia (ese "complejo de antaño" que Lipset y Raab identifican con el impulso de invertir o detener la dirección del cambio que parece estar relacionado con la pérdida de rango), el conservadurismo económico o una debil cultura política democrática. Si en circunstancias no conflictivas estas creencias ultraconservadoras no van más allá de articularse en inocuas protestas contra el sistema, en situaciones de crisis e incertidumbre se extienden en forma de miedo a amplios campos y sectores sociales, que pueden nutrir potentes movimientos políticos y de opinión.

La ideología de la extrema derecha acostumbra a pregonar verdades eternas y valores absolutos basados en tesis pseudocientíficas, en clichés paranoicos (como las diversas teorías de la conspiración) o en tradiciones religioso-culturales que añoran una pretendida «edad de oro» basada en el orden y la autoridad. Presenta además otros rasgos privativos, como el énfasis en el valor de la desigualdad social y política que genera una particular intolerancia nativista, la preeminencia ontológica de las minorías sobre las masas que deriva en diversas formas de elitismo, el apego a la tradición, y un evidente pesimismo antropológico que Sowell identificó como una Weltanschaunng fundamentada en la convicción de que las limitaciones humanas resultan naturales e imposibles de superar $^{7}$. Esta concepción profundamente negativa del progreso humano deriva en tres tesis que Hirschman presenta como características de toda retórica reaccionaria: la tesis de la perversidad, según la cual toda acción deliberada para

5 Bell, Daniel: «The Dispossessed-1962», en Daniel Bell (ed.), The Radical Right, Nueva York, Doubleday, 1963, p. 21, idea retomada por LIPSET y RAAB: La política de la sinrazón, pp. 9 y 529-530.

6 MOLLER, Kurt: «Right Wing Extremism Orientation Among Young People in Reunited Germany», conferencia en la Universidad de York (11-III-1994), cit. por EBATA: «Right Wing Extremism», p. 13.

7 SOWELL, Thomas: Conflicto de visiones. Orígenes ideológicos de las luchas politicas, Barcelona, Gedisa, 1990, pp. 15 ss.

Hispania, LXI/1, núm. 207 (2001) 9-16 
mejorar algún rasgo del orden político, social o económico sólo sirve para exacerbar la situación que se desea remediar; la tesis de la futilidad, que reputa toda tentativa de transformación social como inválida e ineficaz, y la tesis del riesgo, que señala que el costo del cambio o la reforma propuestos siempre es demasiado alto o inaceptable, dado que pone en peligro algún logro previo particularmente apreciado por la población ${ }^{8}$.

La extrema derecha acostumbra a realzar la sacralidad de la nación y de la identidad nacional sobre cualquier otro valor o identidad colectiva. Cada persona se define como miembro de grupos étnicos, nacionales, religiosos o culturales que aparecen estructurados jerárquicamente de acuerdo con un pretendido «orden natural», y ese etnocentrismo puede ser trasladado hacia actitudes agresivas como la xenofobia, el racismo o una política exterior imperialista. Ese rechazo de la alteridad y del igualitarismo tiene más posibilidades de arraigar en instituciones especialmente jerárquicas y corporativas como las Fuerzas Armadas, aunque la vocación intervencionista de los militares no puede vincularse siempre con actitudes extremistas de derecha. En su síntesis sobre la evolución las tendencias ultraderechistas en el Ejército español a lo largo del siglo $\mathrm{XX}$, Carlos Navajas reconoce un substrato general de tono antipartidista, antipolítico y nacionalista en la mentalidad de la corporación militar, pero pone el énfasis en el pluralismo ideológico existente en el primer tercio del siglo, donde convivió un ultraderechismo primario (que se hizo dominante durante la Dictadura primorriverista) con actitudes más moderaradas de carácter conservador y liberal. La hegemonía ideológica de las extremas derechas (falangistas, ultraconservadores, franquistas a secas, etc.) se hizo incontestable en el Ejército del 18 de Julio, transmutado en "partido militar» que actuaba como intérprete y ejecutor supremo de la voluntad nacional. Pero la autonomía de la ideología militarista de extrema derecha declinó de forma irreversible con la Transición a la democracia, cuando, a diferencia de los años de entreguerras, la extrema derecha castrense no se comportó como una fuerza independiente, sino como un mero instrumento de la ultraderecha civil. Esa desesperanza ante el cambio y esa radical intolerancia intelectual no implican, como señalaba Simone de Beauvoir, que el pensamiento de la (extrema) derecha haya sido siempre impreciso, contradictorio, antiintelectualista, irracionalista o idealista, o que haya apelado siempre a la violencia intimidatoria, al culto a la virilidad o a la mística del heroísmo y del sacrificio individuales ${ }^{9}$. Pero no es menos cierto que, a diferencia de la derecha liberal y democrática, que acepta la naturaleza agonística inherente al debate político parlamentario, la extrema derecha ha solido mostrar una actitud polémica de enfrentamiento total, sin fisuras ni concesiones,

8 Hirschman, Albert O.: Retóricas de la intransigencia, México, Fondo de Cultura Económica, 1991, pp. 17-18.

9 BeAuvorr, Simone de: El pensamiento político de la derecha, Buenos Aires, Siglo XXI, 1969, pp. 25 y 147.

Hispania, LXI/1, núm. 207 (2001) 9-16 
donde el adversario se transforma en enemigo susceptible de ser eliminado política e incluso físicamente ${ }^{10}$. Además, su radical catastrofismo le separa de la praxis social reformista que puede asumir de forma eventual el conservadurismo más transigente.

Aunque los tics psicológicos e ideológicos de la extrema derecha arraigan y perviven con inusitada fuerza, su plasmación política ha sido bastante cambiante, lo que ha dificultado su aprehensión en un marco analítico fundamentalmente teórico. Imponer el remoquete de ultraderechista a una corriente de opinión, movimiento o partido no ha sido siempre tarea sencilla. Si entendemos el extremismo como un gradiente relativo que mide el nivel de desviación respecto de la norma política vigente en cada momento, ¿cómo identificar su presencia y aislar sus manifestaciones en regímenes de acusada naturaleza autoritaria y antidemocrática, como el franquismo, el salazarismo o los fascismos de la Europa de entreguerras?. En contrapartida, si lo definimos, en términos absolutos, como una tendencia específica a transgerdir los valores pluralistas, las libertades y los procedimientos normativos que caracterizan el proceso político democrático, cabría preguntarse si existió el extremismo de derechas antes de la consolidación de la democracia parlamentaria, o si cualquier actividad pública que se realiza en el marco de un régimen autoritario aparece automáticamente contaminada por tan nefando apelativo político.

Parece evidente que este tipo de definiciones apriorísticas no aclaran gran cosa. Tampoco los diversos ensayos tipológicos basados en modelos políticos ideales y consolidados de carácter triádico acaban de resolver el problema ${ }^{11}$, puesto que no contemplan en su justa medida el carácter dinámico de este proceso de radicalización. La mejor manera de identificar a la extrema derecha en cada momento sería analizar su actuación y evolución políticas a lo largo del tiempo. Históricamente, la incorporación de nuevas corrientes al extremismo de derechas

10 Freund, Julien: Sociología del conflicto, Madrid, Ministerio de Defensa, 1995, pp. 95 ss.

1 Tanto MAYER, Arno Joseph: Dynamics of Counterrevolution in Europe, 1870-1956, An Analytic Framework Nueva York, Harper Torchbooks, 1971 como Eugen Weber en su introducción a Hans ROGGER y Eugen WeBER (eds.): La derecha europea, Barcelona, Luis de Caralt, 1972, diferenciaban una derecha conservadora (que resistía al cambio, pero lo asumía en la medida que se va incorporando al orden establecido), una derecha reaccionaria (que deseaba retornar a una supuesta «edad de oro») y una derecha radical o contrarrevolucionaria, que aspiraba a imponer rectificaciones sustanciales al sistema sociopolítico liberal. Por su parte, PAYNE, Stanley G.: El fascismo, Madrid, Alianza, 1982, pp. 21-28 e Historia del fascismo, Barcelona, Planeta, 1995, pp. 24-30, divide el nacionalismo autoritario del siglo XX en derecha autoritaria conservadora (que rompió con las formas parlamentarias del conservadurismo moderado, pero seguía basando su doctrina en valores religiosos más que en la nueva mística cultural irracionalista y vitalista, y fue incapaz de abrirse con eficacia a la política de masas), derecha radical (que rechazaba tanto el conservadurismo moderado como el tradicionalismo reaccionario, y buscaba sustituir el régimen liberal por un sistema socioeconómico corporativo) y fascismo como corriente más moderna, en el sentido de querer establecer una nueva relación funcional en la sociedad, la política y la cultura basada en el fomento de la movilización interclasista bajo los moldes de un ultranacionalismo populista con rasgos totalitarios. 
y su mayor o menor capacidad movilizadora han estado en relación dialéctica con la capacidad mostrada por el liberalismo para gestionar y resolver los problemas sociales, políticos y económicos anejos al proceso de modernización. Apoyándonos parcialmente en las oleadas reaccionarias descritas por Hirschman como respuesta a la profundización de los derechos de ciudadanía enunciados por Marshall ${ }^{12}$, aventuraríamos una periodización básica del extremismo derechista fundamentada en la irrupción de varias corrientes sucesivas que tratan de responder a esa paulatina implantación de las libertades civiles y políticas.

En primer lugar, el tradicionalismo como respuesta a la crisis del absolutismo sobrevenida con el desarrollo del pensamiento ilustrado, que intentó la sistematización del hecho religioso como legitimador de un proyecto político cuyo fin último era la consolidación de la alianza entre el Altar y el Trono. Esta doctrina cobraría forma política a caballo de los siglos XVIII y XIX con la aparición de los diversos movimientos contrarrevolucionarios de tipo legitimista, cuya derrota dejaría como secuela el reaccionarismo (término que ingresó en el vocabulario político tras Thermidor, pero cuyos primeros signos se habían dado en las etapas iniciales de la Revolución Francesa) entendido como actitud política contraría a la igualdad ante la ley y a los derechos civiles en general.

En una segunda etapa de consolidación progresiva del liberalismo en la segunda mitad del siglo XIX aparecerían diversos modos de autoritarismo: formas personalistas de gobierno que no cuestionaban el orden socioeconómico liberal, pero que anulaban o coartaban gravemente las libertades cívicas y el gobierno representativo, cuyo espectro de incidencia política iba desde un elitismo vinculado al liberalismo doctrinario hasta dictaduras plebiscitarias de tipo bonapartista.

Desde el último tercio del siglo XIX hasta la Primera Guerra Mundial surgiría la derecha radical como respuesta a la generalización de las libertades individuales, al sufragio universal y a la crisis finisecular del positivismo y el racionalismo. Esta nueva derecha extrema pretendió basar su discurso en nociones pretendidamente científicas extraídas de la biología, la psicología, la sociología o la jurisprudencia, y su proyecto político implicaba la adopción de un sistema corporativo que imponía límites sustantivos al desarrollo del liberalismo clásico.

En este proceso evolutivo, que en absoluto fue tan lineal como acabamos de esquematizar, el fascismo debiera contemplarse como un útil indicador de los límites máximos a los que tendía la dinámica política de la extrema derecha en un período convulso como fueron los años de entreguerras. El fascismo habría de entenderse, por tanto, como la manifestación paroxística de una derecha revolucionaria que actuó frente a la crisis del liberalismo y la irrupción de la sociedad de masas y del socialismo con una peculiar mezcolanza de elementos voluntaris-

12 HiRschman: Retóricas de la intransigencia, pp. 14-18 y MARSHALL, Thomas Humphrey: Class, Citizenship, and Social Development, Nueva York, Doubleday, 1964.

Hispania, LXI/1, núm. 207 (2001) 9-16 
tas, nacionalistas, anticonservadores, antiliberales, elitistas y populistas, que se concretan en rasgos políticos como el antimarxismo, el militarismo, el liderazgo autoritario y carismático, la implantación de un Estado totalitario controlado por un partido, un nacionalismo excluyente y proyectivo, una economía dirigida de naturaleza corporativa, la movilización permanente de la población o la exaltación de lós aspectos místicos y emocionales de la adhesión multitudinaria mediante la adopción de una liturgia política compleja y espectacular.

El declive de los totalitarismos y la crisis de la modernidad ha generado en los últimos años una abigarrada línea de pensamiento que moviliza argumentos procedentes del liberalismo económico, pero cuyas consecuencias en el orden político y cultural son profundamene regresivas. Esta corriente intelectual, que en Estados Unidos se ha llamado neoconservadurismo y. en Francia Nueva Derecha, exalta el libre mercado y propugna una revigorización intelectual y moral del capitalismo que debe alcanzarse mediante la prescripción de una terapia social disciplinaria basada en la imposición de normas, valores e instituciones tradicionales que deben hacer frente a la supuesta desintegración moral y espiritual que afecta a la moderna sociedad secularizada. El neoconservadurismo se presenta como alternativa individualista al fracaso de la misión redentora del radicalismo de izquierdas y a los problemas de sostenimiento de las políticas igualitarias impulsadas por el Estado benefactor de origen keynesiano. Estos problemas de gobernabilidad del capitalismo tardío tratan de ser resueltos con un rearme moral y con la adopción de prácticas políticas de carácter neocorporativo ${ }^{13}$.

En definitiva, no ha existido una, sino varias tradiciones de extrema derecha, la más antigua de las cuales es el pensamiento contrarrevolucionario. Pedro Carlos González Cuevas resalta en su trabajo que, en la configuración ideológica de la extrema derecha española, la influencia omnipresente y determinante fue, hasta el siglo XX, la católica tradicional, que contribuyó a configurar un tipo de cultura política cuya base fue la idea del súbdito alejado del ámbito de la actividad política, acostumbrado a desconfiar de la misma y que presta su aquiescencia pasiva a la labor de unos gobernantes que se reservan el monopolio de la gestión y de la decisión sobre los asuntos de la colectividad. Dentro de esta tradición dominante de tipo teológico-político se han perfilado dos tendencias subalternas: la legitimista-carlista, o tradicionalista a secas, partidaria de la restauración de la alianza entre el Altar y el Trono, y la conservadora autoritaria, nacida de una percepción más consciente de las nuevas realidades sociales, que trata de aglutinar los elementos básicos de la sociedad tradicional con una aceptación parcial del cambio social, sobre todo en la esfera

13 La bibliografía sobre las diferentes tendencias intelectuales del neoconservadurismo es, a estas alturas, ingente. Una síntesis accesible sobre la cuestión, en OLIET PALÁ, Alberto: «Neoconservadurismo", en Fernando VALLESPÍN (ed.), Historia de la teoría política, vol. 5: Rechazo y desconfianza en el proyecto ilustrado, Madrid, Alianza, 1994, pp. 397-489. 
económica, mientras que la extrema derecha radical de tono fascista sería puramente residual en este proceso. El contrapunto a la tesis del arcaísmo ideológico dominante en las extremas derechas españolas lo ofrece Ismael Saz en su estudio sobre la peripecia política del fascismo autóctono, donde rechaza el "paradigma del atraso", tan atacado por la historiografía reciente. Saz no propone una "normalización» acrítica que explique la incidencia política de las actitudes o movimeintos antiliberales en clave de paréntesis o de accidente, sino que reivindica que el fascismo y el régimen franquista se estudien por separado en tanto que problemas diferenciados. Reclama además que los orígenes ideológicos y culturales de la derecha española del siglo XX se analicen en su relación de continuidad con corrientes homólogas europeas, superado todo dique historiográfico o enfoque casticista.

Lo que no cabe duda es que el franquismo marcó por largo tiempo los límites del proceso de aggiornamento ideológico y político del ultraderechismo y de la derecha española en general. Xavier Casals considera ilustrativo que la extrema derecha en su conjunto haya sido incapaz de adoptar un lenguaje y simbología que le permitan modernizar su discurso, su estética y su imagen, y que las tendencias vanguardistas radicales siempre hayan sido minoritarias sobre los sectores fundamentalmente tradicionales definidos por el integrismo católico y la nostalgia del franquismo ${ }^{14}$. ¿Excepcionalidad o normalidad? ¿Casticismo o europeísmo? ¿Arcaísmo o modernidad? Esperamos que las páginas que siguen aporten elementos que permitan ilustrar y enriquecer este interesante debate en marcha.

14 CASALS, Xavier:" «La ultraderecha española: ¿Una modernización imposible?», en Manuel PÉREZ LEDESMA (comp.), Los riesgos para la democracia. Fascismo y neofascismo, Madrid, Ed. Pablo Iglesias, 1997, p. 171-172. 